06

\title{
Структурные свойства и состав графитоподобных углеродных пленок, полученных импульсным лазерным испарением
}

\author{
(С) И.В. Ершов, Н.В. Пруцакова, О.М. Холодова, А.А. Лаврентьев, И.В. Мардасова, Т.П. Жданова \\ Донской государственный технический университет, \\ 344000 Ростов-на-Дону, Россия \\ e-mail: iershov@donstu.ru
}

Поступило в Редакцию 31 августа 2020 г.

В окончательной редакции 21 октября 2020 г.

Принято к публикации 26 октября 2020 г.

Исследованы структура и состав графитоподобных углеродных пленок, полученных методом импульсного лазерного осаждения в атмосфере инертного газа с использованием сублимируемых углеродных лент. Полученные пленки были изучены с помощью рентгеновской дифракции, фотоэлектронной спектроскопии и спектроскопии комбинационного рассеяния света. Рентгеноструктурный анализ показал, что полученные пленки имеют структуру, характерную для турбостратного углерода и восстановленного оксида графена. Анализ фотоэлектронных спектров позволил сделать вывод о значительном уменьшении содержания кислорода и водорода в полученных пленках по сравнению с материалом мишени, а также о значительном снижении содержания $s p^{3}$-фазы. С использованием спектроскопии комбинационного рассеяния было показано, что углеродные пленки имеют характерные признаки нанокристаллического графита/графена и двумерную (турбостратную) структуру с характерными размерами $s p^{2}$-кристаллитов порядка $15-18 \mathrm{~nm}$ в зависимости от плотности энергии лазерного импульса.

Ключевые слова: нанокристаллический графит, турбостратная структура, спектроскопия комбинационное рассеяние света, рентгеновская фотоэлектронная спектроскопии, импульсное лазерное осаждение.

DOI: $10.21883 /$ JTF.2021.04.50627.257-20

\section{Введение}

Неупорядоченные и кристаллические углеродные пленки уже достаточно давно привлекают повышенное внимание благодаря широкому спектру их применения [1-3]. Широкий спектр свойств углеродных материалов обусловлен полиморфизмом структурных конфигураций углерода как в кристаллическом, так и в аморфном состояниях. Среди кристаллических форм углерода наибольший интерес вызывают различные модификации $s p^{2}$-углерода, например, нанотрубки, одно- и многослойные графены [4,5] в связи с перспективами их применения в наноэлектронике. Среди аморфных углеродных материалов широкое применение находят как графитоподобный (GLC), так и алмазоподобный углерод (DLC) [6] с высоким содержанием $s p^{3}$-фазы.

Аморфные углеродные пленки находят применение в устройствах энергонезависимой памяти за счет структурных фазовых переходов, которые могут происходить под действием высоких температур и электрических полей $[7,8]$. Механизм такого переключения проводимости основан на изменении соотношения $s p^{2} / s p^{3}$-фаз в аморфном углероде. В то время как алмазоподобная фаза характеризуется малой проводимостью за счет преобладания атомов углерода в состоянии $s p^{3}$-гибридизации, графитоподобная фаза, состоящая из фрагментов графитовых плоскостей и изогнутых фуллереноподобных фрагментов с преимущественно $s p^{2}$-углеродом, наоборот, характеризуется высокой электропроводно- стью. Покрытия из графитоподобного углерода имеют хорошие перспективы использования в области трения и износа [1], также GLC находит применение в технологии низкотемпературной совместно обжигаемой керамики (LTCC), которая применяется для создания микроволновых излучающих устройств $[9,10]$.

К настоящему времени существует достаточно большое количество разнообразных методов получения как кристаллических, так и аморфных углеродных пленок [11-13]. Среди методов физического осаждения импульсное лазерное осаждение (PLD) зарекомендовало себя одной из наиболее универсальных технологий выращивания тонких пленок. Метод PLD по сравнению с другими методами химического и физического осаждения является концептуально простым, гибким, эффективным и малозатратным, он позволяет получать пленки с химическим составом, идентичным составу мишени благодаря быстропротекающему процессу лазерной абляции, а также легко позволяет получать легированные материалы со сложным составом. Изменяя параметры лазерного излучения с помощью метода PLD, можно добиться формирования аморфных углеродных пленок [13,14], фуллеренов и нанотрубок, графитовых слоев [15], а также многослойных графеновых пленок [16,17].

В настоящей работе были изучены структура и состав углеродных пленок, полученных методом импульсного лазерного осаждения из сублимируемого графитоподобного углерода в атмосфере инертного газа. Полученные пленки были исследованы с помощью рентгеновской 
дифракции, фотоэлектронной спектроскопии (РФЭС) и спектроскопии комбинационного рассеяния света (КРС).

\section{1. Материалы и методика эксперимента}

В качестве материала мишени для лазерной абляции использовалась углеродная лента марки TCS-CARB-1 (нанокарбон) от производителя C12 Advanced Technologies [18], в состав которой входит микро/нанокристаллический аморфный графитоподобный углерод высокой спектральной чистоты, а также органическое связующее и дисперсант, которые полностью распадаются в диапазоне температур от 130 до $350^{\circ} \mathrm{C}$. Продуктами распада связующего являются молекулы воды, моно- и диоксид углерода, фрагменты углеводородов.

Материал мишени и полученные углеродные пленки были исследованы с помощью рентгеновской дифракции для определения его структурных параметров. Рентгенодифрактометрические измерения проводились на дифрактометре ДРОН-3М с использованием $\mathrm{Cu} K_{\alpha}$-излучения методом фокусировки по Брэггу-Брентано в пошаговом режиме сканирования с шагом $0.01^{\circ}$ и временем экспозиции в каждой точке $8 \mathrm{~s}$. Ток трубки составлял $15 \mathrm{~mA}$, ускоряющее напряжение $-30 \mathrm{kV}$. Химический состав мишени и углеродных пленок изучался с помощью рентгеновской фотоэлектронной спектроскопии. Фотоэлектронные спектры были получены с помощью системы анализа поверхности ESCALAB 250 с монохроматором. Энергетическое разрешение, измеренное на линии $\mathrm{Ag} 3 d_{5 / 2}$, составляло $0.6 \mathrm{eV}$.

Для получения углеродных пленок была произведена абляция мишени из нанокарбона с использованием излучения неодимового лазера на алюминий-иттриевом гранате $\mathrm{Nd}$ :YAG в режиме модулированной добротности. Длительность импульса составляла $40 \mathrm{~ns}$. Излучение фокусировалось под углом падения $45^{\circ}$ к плоскости мишени, подложки из оксида алюминия и серебра ориентировались по нормали к лазерному факелу. На подложках оксида алюминия были получены 2 образца, нанесенных при разных режимах. Первый образец GLC/alumina-1 получен путем испарения мишени при плотности энергии лазерного импульса $6 \mathrm{~J} / \mathrm{cm}^{2}$, второй образец GLC/alumina-2 соответственно был получен при плотности энергии $4 \mathrm{~J} / \mathrm{cm}^{2}$. Для исследования с использованием РФЭ-спектроскопии был получен образец на подложке из серебра. Частота повторения импульсов составляла $500 \mathrm{~Hz}$, время осаждения - $4 \mathrm{~s}$. Испарение происходило в реакторе, через который прокачивался гелий при атмосферном давлении.

Следует заметить, что излучение неодимового лазера характеризуется энергией фотона $1.16 \mathrm{eV}$, в то же время энергия ковалентной $\mathrm{C}=\mathrm{C}$-связи в структуре графита/графена составляет $3.7 \mathrm{eV}$. Таким образом, при воздействии лазерного пучка на материал мишени не происходит разрушения этих связей за счет фотоионизации, поэтому размер углеродных кластеров будет определяться плотностью энергии лазерного излучения. Как показывают результаты время-пролетной масс-спектроскопии углеродных кластеров, образованных в результате испарения графитовых мишеней излучением неодимового лазера [19], при воздействии пучками с плотностью энергии выше $2.3 \mathrm{~J} / \mathrm{cm}^{2}$ образуются преимущественно кластеры $C_{1}^{+}(>70 \%)$ и $C_{3}^{+}(<30 \%)$.

Для дальнейшего анализа полученных углеродных пленок были проведены исследования с использованием спектроскопии комбинационного рассеяния света. Были получены спектры углеродных пленок, нанесенных на подложки поликристаллического оксида алюминия. Спектры КРС возбуждались поляризованным излучением аргонового лазера на длине волны $514.5 \mathrm{~nm}$ (энергия фотона $2.41 \mathrm{eV}$ ) и регистрировались спектрометром Renishaw inVia Raman Microscope. Возбуждающее излучение лазера фокусировалось на поверхности образцов с помощью 50-кратного объектива в пятно диаметром $4 \mu \mathrm{m}$.

\section{2. Результаты и их обсуждение}

Полученные углеродные пленки в виде пятна (диаметром $\approx 10 \mathrm{~mm}$ ) имели неоднородную структуру, их толщина имела наибольшее значение в центре и уменьшалась в направлении краев. На дифрактограмме мишени (nanocarbon) (рис. 1) прослеживаются два основных пика при углах $2 \theta=25^{\circ}$ и $2 \theta=43^{\circ}$, что примерно соответствует отражениям от плоскостей графита $(002)$ и (100) соответственно. Полученная дифрактограмма характерна для турбостратного графита [20] и сходна с дифрактограммами технического углерода [21] как по положению пиков, так и по их ширине. Расчет для среднего расстояния между плоскостями $s p^{2}$-углерода в нанокарбоне дает значение $0.37 \mathrm{~nm}$. По уширению пиков с помощью формулы Шеррера были сделаны оценки размеров кристаллитов в направлениях [001] и

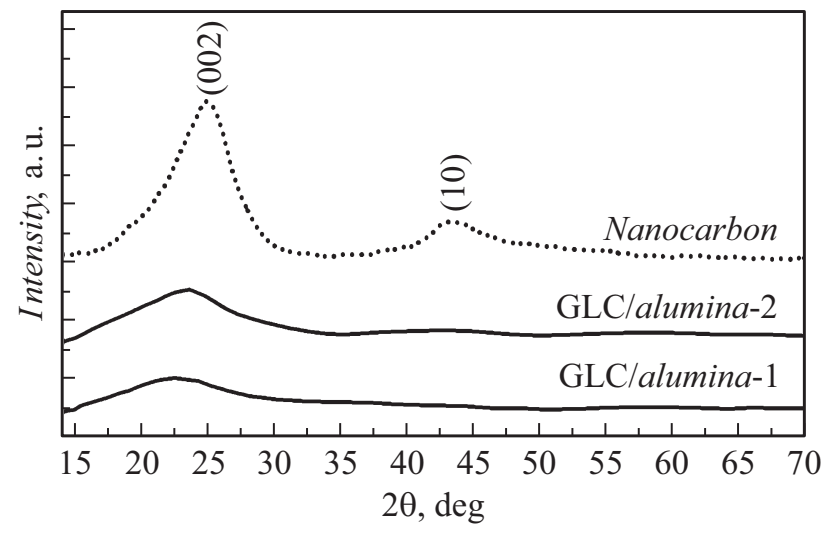

Рис. 1. Дифрактограммы материалов мишени и углеродных пленок. 

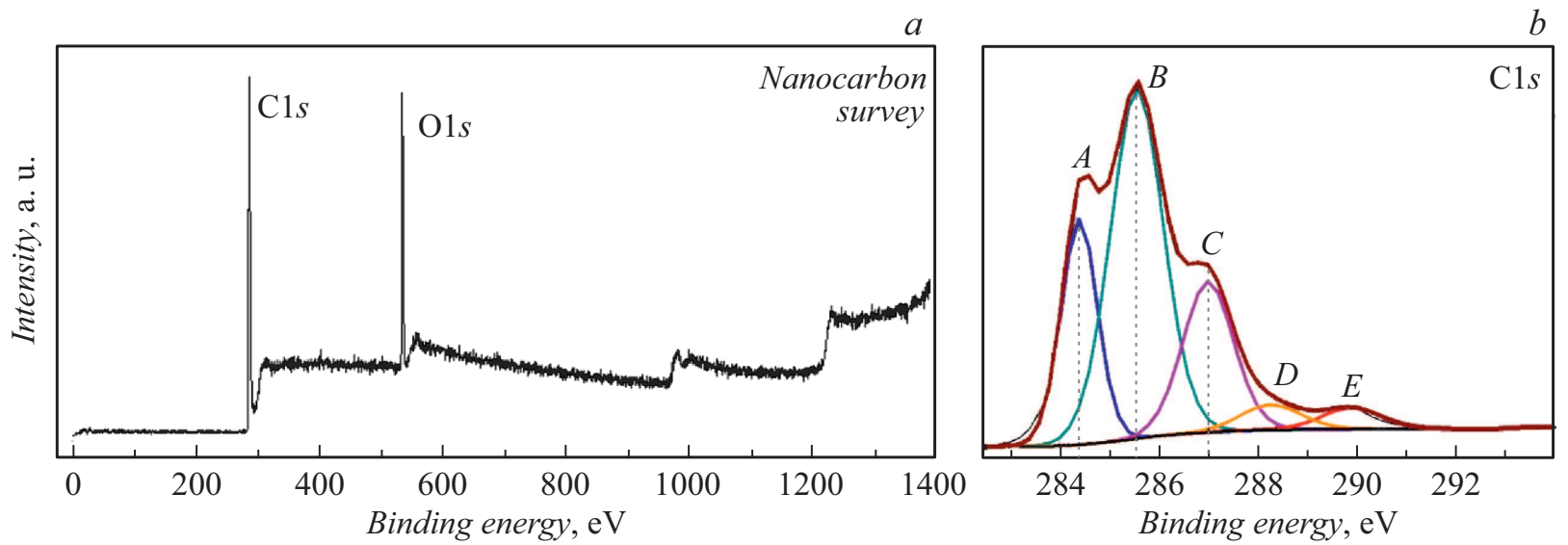

Рис. 2. Рентгеновские фотоэлектронные спектры материала мишени: обзорный $(a)$ и спектр $1 s$-линии углерода $(b)$.

Таблица 1. Процентное содержание различных углеродных связей в материале мишени и углеродной пленке, осажденной на серебре

\begin{tabular}{|c|c|c|c|c|c|c|}
\hline $\mathrm{C} 1 s$ & $A$ & $B$ & $C$ & $D$ & $E$ & $s p^{2} / s p^{3}$ \\
\hline & $\mathrm{C}=\mathrm{C}\left(s p^{2}\right)$ & $\begin{array}{l}\mathrm{C}-\mathrm{C}\left(s p^{3}\right) \\
\mathrm{C}-\mathrm{COOH}\end{array}$ & $\begin{array}{c}\mathrm{C}-\mathrm{O}-\mathrm{C} \\
\mathrm{C}-\mathrm{OH}\end{array}$ & $\mathrm{C}=\mathrm{O}$ & $\mathrm{O}=\mathrm{C}-\mathrm{OH}$ & \\
\hline Нанокарбон & $\begin{array}{c}21 \% \\
(284.3 \mathrm{eV})\end{array}$ & $\begin{array}{c}46.4 \% \\
(285.6 \mathrm{eV})\end{array}$ & $\begin{array}{c}22.2 \% \\
(287 \mathrm{eV})\end{array}$ & $\begin{array}{c}5.2 \% \\
(288.3 \mathrm{eV})\end{array}$ & $\begin{array}{c}5.2 \% \\
(289.9 \mathrm{eV})\end{array}$ & 0.47 \\
\hline GLC/Ag & $\begin{array}{c}59.3 \% \\
(284.4 \mathrm{eV})\end{array}$ & $\begin{array}{c}23.6 \% \\
(285.3 \mathrm{eV})\end{array}$ & $\begin{array}{c}12.4 \% \\
(286.7 \mathrm{eV})\end{array}$ & $\begin{array}{c}4.7 \% \\
(288.5 \mathrm{eV})\end{array}$ & - & 2.51 \\
\hline
\end{tabular}

[100], которые составили приблизительно 1.6 и $3.1 \mathrm{~nm}$ соответственно [22].

Полученные дифрактограммы углеродных пленок на подложке оксида алюминия GLC/alumina (рис. 1) оказались сходными между собой и демонстрируют турбостратную графитоподобную структуру, характерную также для турбостратного многослойного графена и восстановленного оксида графена $[5,20,23,24]$. На дифрактограммах прослеживается один широкий хорошо различимый пик с максимумом $2 \theta \approx 23^{\circ}$ и слабо различимый пик в районе $2 \theta \approx 43^{\circ}$ в образце GLC-alumina-2, которые также наблюдались в материале мишени, однако пик, соответствующий отражению (002), сдвинут в область меньших углов, что говорит об увеличении среднего расстояния между плоскостями $s p^{2}$-углерода. Это расстояние по нашим оценкам возросло до $0.38 \mathrm{~nm}$. Такие структуры могут состоять как из плоских графитовых слоев, так и из изогнутых фуллереноподобных фрагментов [25]. Грубая оценка размера кристаллита в направлении [001] по формуле Шеррера дала значение $1.4 \mathrm{~nm}$, что соответствует 3-4 слоям турбостратного графена.

На рис. 2 приведены обзорный РФЭ-спектр поверхности нанокарбона и спектр внутреннего $1 s$-уровня углерода. Из обзорного спектра видно, что в материале присутствуют соединения углерода и кислорода. Рас- смотрим тонкую структуру спектра $\mathrm{C} 1 s$. Идентификация компонент проводилась по данным источников [26-32]. Энергии компонент приведены в табл. 1.

Компонента $A$ в интервале энергий 284-284.8 eV характерна для $\mathrm{C}=\mathrm{C}$-связи, типичной для графитоподобного углерода с $s p^{2}$-координацией [26]. В диапазоне энергий 285-285.6 eV компонента $B$ обусловлена образованием $s p^{3}$-координированного углерода в результате появления структурных дефектов, а также за счет адсорбции карбоксильных групп $(\mathrm{C}-\mathrm{COOH})$. Кроме того, в диапазоне энергий 285.4-286 eV основной вклад в интенсивность пика $B$ дает связь $\mathrm{C}-\mathrm{H}$, эта связь относится к $s p^{3}$-координированному углероду, который содержится в веществе связующего и дисперсанта. Согласно работам [27-29], компоненту $C$ (энергия связи электронов $286.5-287.3 \mathrm{eV}$ ) мы относим к связи С-O, которая входит в большом количестве в состав органического связующего, а также может присутствовать непосредственно на поверхности $s p^{2}$-углерода в виде эпоксидных колец. Кроме того, в том же диапазоне компонента $C$ также обусловлена наличием связи С-OH. Гидроксильные группы входят как в состав связующего, так и могут непосредственно образовывать связи с $s p^{2}$ - или $s p^{1}$-углеродом (фенолы). Компонента $D$ (энергия связи электронов в диапазоне $288.4-288.7 \mathrm{eV}$ ) соответствует двойной $\mathrm{C}=\mathrm{O}$-связи $[30,31]$, которая характерна для кар- 


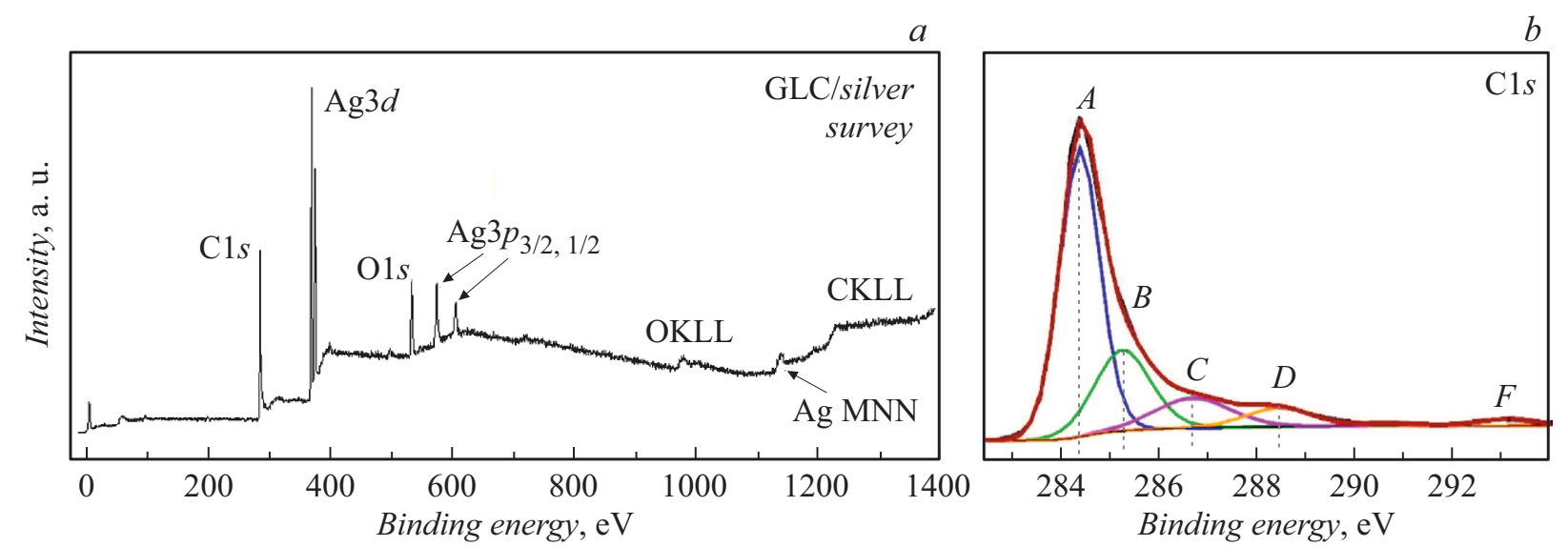

Рис. 3. Рентгеновские фотоэлектронные спектры углеродной пленки, нанесенной на подложку из серебра, обзорный ( $a$ ) и спектр $1 s$-линии углерода $(b)$.

бонильных групп органических дисперсантов, и также может образовываться на краевых атомах углерода в графеновых плоскостях. Компонента $E$ в $\mathrm{C} 1 s$-спектре нанокарбона относится к связи типа $\mathrm{O}=\mathrm{C}-\mathrm{O}$, т.е. свидетельствует о присутствии карбоксильных групп.

На рис. 3 представлены обзорный фотоэлектронный спектр углеродной пленки, нанесенной на серебряную подложку, и спектр внутреннего $1 s$-уровня углерода. На обзорном спектре можно наблюдать $1 s$-уровни углерода и кислорода, а также $\mathrm{Ag} 3 d$ - и $3 p$-линии (дублеты) подложки и линии оже-электронов. Наиболее полное представление о химической связи в полученных углеродных пленках дало РФЭС-изучение тонкой структуры $1 s$-уровня углерода. Анализ спектров и энергетических положений компонент $\mathrm{C} 1 s$-спектров показывает, что они хорошо согласуются с $\mathrm{C} 1 s$-спектром нанокарбона. Энергии компонент приведены в табл. 1. РФЭ $\mathrm{C} 1 s$-спектры углеродных пленок, как и у нанокарбона, имеют по пять компонент, относящихся к различным связям с углеродом и кислородом (рис. 3).

Компонента $A$ в интервале энергий 284-284.8 eV характерна для $\mathrm{C}=\mathrm{C}$-связи, типичной для графита $\mathrm{c}$ $s p^{2}$-координацией [26], положение этого пика полностью совпадает с аналогичным пиком в материале мишени. Компонента $B$ в диапазоне энергий $284.8-285.8 \mathrm{eV}$ отражает вклад $s p^{3}$-углерода в материале углеродной пленки, однако в отличие от аналогичного пика в материале мишени эта компонента смещена в сторону меньших энергий связи и имеет значительно меньшую интенсивность по отношению к пику А. Последнее можно объяснить значительным уменьшением содержания связующего и дисперсанта, и, как следствие, содержания связей $\mathrm{C}-\mathrm{H}$. По соотношению площадей компонент $A / B$ можно оценить отношение долей $s p^{2} / s p^{3}$-фракций в углеродной пленке [33], которое по нашим оценкам составляет 2.5. Уменьшение интенсивности компоненты $B$ отчасти также обусловлено потерей карбоксильных групп графеновыми слоями, что подтверждается исчезновением пика $E$ в спектре пленки по сравнению с материалом мишени.

Согласно работам [27-29], компоненту $C$ (энергия связи электронов 286-287.4 eV) мы относим к связи $\mathrm{C}-\mathrm{O}$ и $\mathrm{C}-\mathrm{OH}$. По сравнению с материалом мишени компонента C смещена в сторону меньших энергий связи и имеет значительно меньшую интенсивность, что может свидетельствовать о потере кислорода из эпоксидных и гидроксильных групп в результате абляции и уменьшении доли эпоксидных групп по отношению к гидроксильным. Компонента $D$ (энергия связи электронов $288.4-288.7 \mathrm{eV}$ ) соответствует $\mathrm{C}=$ О-связи [30,31], интенсивность этой компоненты свидетельствует о том, что содержание кислорода в карбонильных группах по сравнению с материалом мишени также уменьшилось. Следует отметить появление компоненты $F$, которая интерпретируется как $\pi \pi^{*}$-shake up сателлит [34], что может свидетельствовать об увеличении доли $s p^{2}$-углерода.

На рис. 4 приведены спектры КРС для двух образцов углеродных пленок, полученных на подложке $\mathrm{Al}_{2} \mathrm{O}_{3}$. В первую очередь следует отметить в полученных образцах наличие интенсивных полос рассеяния $G$ $\left(\sim 1586 \mathrm{~cm}^{-1}\right), D\left(\sim 1357 \mathrm{~cm}^{-1}\right)$ и $2 D\left(\sim 2700 \mathrm{~cm}^{-1}\right)$, которые характерны для всех углеродных материалов с графитоподобной структурой и $s p^{2}$-координированными атомами C, включая аморфный углерод [35].

Как известно [35-37], возникновение линии $G$ в графите $\left(1581 \mathrm{~cm}^{-1}\right)$ и графитоподобных углеродных материалах обусловлено рассеянием на фононах $E_{2 g}$ симметрии в центре зоны Бриллюэна. Появление $E_{2 g}$-моды возможно не только в шестичленных углеродных кольцах, но также наблюдается в различных цепочках $s p^{2}$-углерода, характерных для аморфного углерода. Таким образом, наличие пика $G$ позволяет говорить о присутствии в образце $s p^{2}$-углерода. Линия $D$ в спектре КРС появляется за счет неупругого рассеяния возбужденных электронов на фононах симметрии $A_{1 g}$, и упругого рассеяния этих электронов на дефектах. Появление линии $D$ 


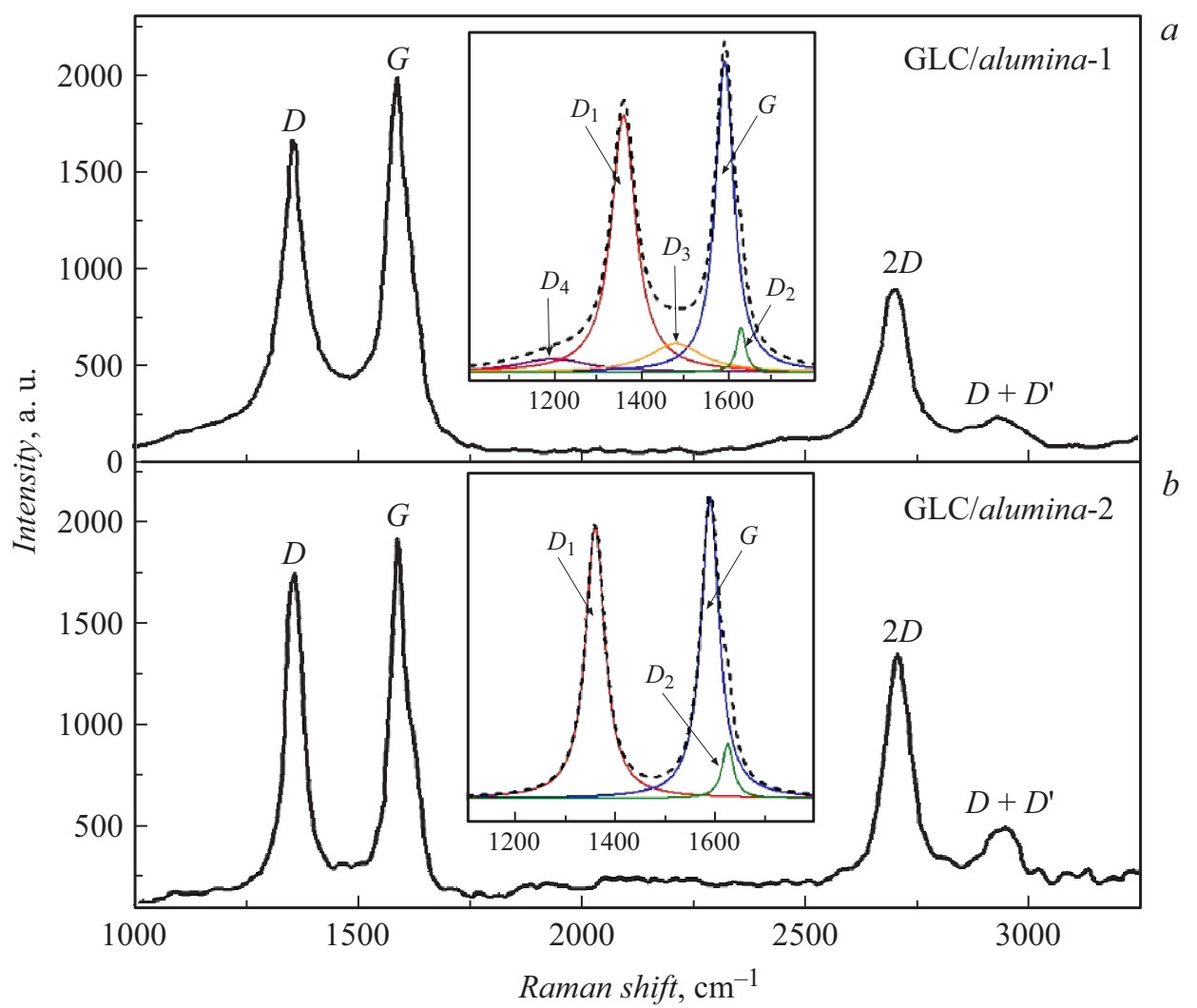

Рис. 4. Спектры КРС образцов углеродных пленок, осажденных на оксиде алюминия, на вставках спектры первого порядка, разрешенные на компоненты.

Таблица 2. Позиции основных пиков в спектрах КРС, полная ширина линий на половине максимума (FWHM), отношение интегральных интенсивностей $\left(I_{D} / I_{G}\right)$ пиков $D$ и $G$, а также оценка размеров $s p^{2}$-кристаллитов $\left(L_{a}\right)$

\begin{tabular}{|c|c|c|c|c|c|c|c|c|c|}
\hline & \multicolumn{4}{|c|}{ Позиция, $\mathrm{cm}^{-1}$} & \multicolumn{3}{|c|}{ FWHM, $\mathrm{cm}^{-1}$} & \multirow{2}{*}{$I_{D} / I_{G}$} & \multirow{2}{*}{$L_{a}, \mathrm{~nm}$} \\
\hline & $D$ & $G$ & $2 D$ & $D^{\prime}$ & $D$ & $G$ & $2 D$ & & \\
\hline GLC/alumina-1 & 1356 & 1587 & 2701 & 1623 & 67 & 50 & 76 & 1.11 & 15.3 \\
\hline GLC/alumina-2 & 1358 & 1586 & 2707 & 1621 & 45 & 43 & 63 & 0.96 & 17.7 \\
\hline
\end{tabular}

говорит о присутствии шестичленных углеродных колец и наличии структурного разупорядочения в идеальной гексагональной структуре (дефекты, границы зерен, адсорбаты). В отличие от линии $D$, линия $2 D$ не связана c наличием дефектов и наблюдается в большинстве углеродных материалов с графитоподобной структурой $\left(\sim 2700 \mathrm{~cm}^{-1}\right)$. Возникновение полосы $2 D$ обусловлено рассеянием на двух фононах с одинаковым импульсом. Обе линии $D$ и $2 D$ появляются в результате двойного резонанса (табл. 2).

Помимо трех указанных наиболее интенсивных линий в спектрах КРС наблюдаются дополнительные линии, например, в области частот от 2800 до $3000 \mathrm{~cm}^{-1}$ в обоих образцах наблюдаются полосы, обозначенные как $D+D^{\prime}\left(\sim 2940 \mathrm{~cm}^{-1}\right)$. Эти полосы также связаны с двухфононными процессами рассеяния в присутствии дефектов [38]. Кроме того, на рис. 4 (вставки) линии первого порядка рассеяния разложены на компоненты с использованием функций Лоренца. На рис. 4, a (вставка) мы можем наблюдать дополнительные рамановские пики $D_{2}\left(D^{\prime}\right), D_{3}$ и $D_{4}$. Пик $D^{\prime}\left(\sim 1620 \mathrm{~cm}^{-1}\right)$ обусловлен двойным резонансом в окрестности точки $K$ зоны Бриллюэна и может появляться только в присутствии дефектов, на которых могут рассеиваться электроны. Пики $D_{3}$ и $D_{4}$ более сложны для интерпретации, обычно эти полосы присутствуют в высокодефектных образцах, полосу $D_{3}$ относят к присутствию $s p^{3}$-углерода между $s p^{2}$-областями [21,39], причем отношение интенсивностей пиков $I_{D_{3}} / I_{G}$ характеризует степень аморфизации и пропорционально содержанию $s p^{3}$-углерода. Экспериментальные данные также свидетельствуют об исчезновении полосы $D_{3}$ при нагревании образцов выше темпе- 
ратуры $1500^{\circ} \mathrm{C}$ [21]. Полоса $D_{4}$ соответствует наличию углеводородов, присоединенных к базальной поверхности графита $[21,40]$ и также исчезает при температуре выше $1200^{\circ} \mathrm{C}$. Следует отметить, что в спектре образца 2 (рис. $4, b$ ) пики $D_{3}$ и $D_{4}$ отсутствуют.

Интенсивность линии $D$, как известно [37,41,42], пропорциональна числу рассеивающих центров, а следовательно, и среднему размеру зерен $L_{a}$ в графеновых плоскостях. Таким образом, отношение интенсивностей пиков $D$ и $G$ широко используется для оценки параметpa $L_{a}$. Для данной длины волны возбуждающего лазерного излучения $\lambda_{l}$ можно использовать формулу [42]:

$$
L_{a}[\mathrm{~nm}]=2.4 \cdot 10^{-10} \lambda_{l}^{4}\left(I_{D} / I_{G}\right)^{-1} .
$$

Внедрение дефектов в идеальную структуру графита, изменение углов и длин связей, гибридизация приводят к постепенной аморфизации углерода. Из анализа полученных спектров КРС следует, что образцы углеродных пленок могут относиться к первой или второй стадии аморфизации согласно $[35,43]$. Для определения стадии аморфизации можно использовать положение и ширину линии $G$ [44], и отношение $I_{D} / I_{G}$. Наличие связей $\mathrm{C}-\mathrm{H}$ не дает заметного вклада в линии $D$ и $G$ кроме их уширения за счет сокращения размеров кристаллитов [35]. Для полученных нами пленок наблюдается сдвиг линии $G$ относительно монокристаллического графита на 6 и $5 \mathrm{~cm}^{-1}$ соответственно для 1 и 2 образцов. Соотношение абсолютных интенсивностей $I_{D} / I_{G}$ для образцов 1 и 2 составило соответственно 0.84 и 0.91 . По ширине линии $G$ можно предварительно оценить минимальные размеры кристаллитов $L_{a}$ [44], которые для наших образцов составляют от 6 до $10 \mathrm{~nm}$. Согласно данным [35,36], указанным характерным размерам кристаллитов соответствует первая стадия аморфизации, для которой справедливо выражение (1). Таким образом, можно сделать вывод, что образцы пленок по степени структурного упорядочения представляют собой нанокристаллический графит или многослойный разупорядоченный графен. Характерные размеры кристаллитов были оценены с помощью выражения (1) с использованием интегральных интенсивностей пиков $D$ и $G$, и составили 15.3 и $17.7 \mathrm{~nm}$ соответственно для образцов 1 и 2. Указанные особенности спектров КРС позволяют сделать вывод о том, что образец углеродной пленки GLC/alumina-1 имеет меньшую степень структурного упорядочения по сравнению с образцом GLC/alumina-2, что может быть связано с более высоким значением энергии лазерного импульса [18].

В работе [45] было показано, что по отношению интенсивностей пиков $D$ и $D^{\prime}$ можно сделать выводы о преобладающем типе дефектов в образцах двумерного графита и графена, находящихся на первой стадии аморфизации. В частности, для образца GLC/alumina-1 соотношение $I_{D} / I_{D^{\prime}}$ составляет $\sim 5$, что может говорить о преобладании точечных дефектов (вакансий), в то же время для образца GLC/alumina-2 это соотношение составляет порядка 3.8 , что может указывать на преобладание линейных дефектов типа границ зерен. По структуре линии второго порядка $2 D$ можно судить о степени упорядочения слоев $s p^{2}$-углерода в направлении [001]. Для полученных пленок линия $2 D$ аппроксимируется одиночной функцией Лоренца, центрированной на частоте 2701 и $2707 \mathrm{~cm}^{-1}$ соответственно для 1 и 2 образцов. Это свидетельствует об отсутствии упорядочения в направлении $[001][46,47]$ и может быть связано с увеличением расстояния между слоями и их случайной взаимной ориентации подобно турбостратному графиту/графену [36]. По соотношению интенсивностей пиков $G$ и $2 D$ аналогично работе [48] можно сделать приблизительную оценку толщины пленок в центре пятна, которая составила не менее 21 монослоя $s p^{2}$-углерода.

\section{Заключение}

В работе были исследованы структурные свойства и состав углеродных пленок, полученных с помощью импульсного лазерного испарения сублимируемых углеродных лент. Исследования показали, что полученные пленки имеют графитоподобную структуру с низким содержанием $s p^{3}$-фазы и могут быть отнесены к нанокристаллическому дефектному турбостратному графиту или графену. Турбостратная структура пленок подтверждается рентгеновскими дифрактограммами и формой линии второго порядка $2 D$ в спектрах комбинационного рассеяния. С помощью фотоэлектронной спектроскопии была получена информация о химическом составе углеродных пленок и функциональных группах, которые адсорбируются на поверхности пленок, на дефектах и между слоями. В частности, РФЭ-спектры позволили сделать вывод о значительном уменьшении содержания кислорода и водорода в полученных пленках по сравнению с материалом мишени под воздействием лазерного излучения. Анализ спектров КРС также позволил определить стадию аморфизации углеродных пленок и сделать оценки размеров $s p^{2}$-кристаллитов. В частности, было показано, что в режиме испарения с меньшей плотностью энергии лазерного импульса полученные пленки характеризуются бо́льшими размерами $s p^{2}$-кристаллитов и меньшей дефектностью.

\section{Благодарности}

Авторы выражают благодарность проф. Козакову А.Т. (НИИ Физики ЮФУ) за помощь в выполнении экспериментов с использованием рентгеновской фотоэлектронной спектроскопии, а также Авраменко М.В. (кафедра „Нанотехнология“ ЮФУ) за получение рамановских спектров углеродных пленок на оксиде алюминия.

\section{Конфликт интересов}

Авторы заявляют, что у них нет конфликта интересов. 


\section{Список литературы}

[1] M. Huang, X. Zhang, P. Keb, A. Wang. Appl. Surf. Sci., 283, 321 (2013). DOI: 10.1016/j.apsusc.2013.06.109

[2] C. Greco, U. Cosentino, D. Pitea, G. Moro, S. Santangelo, S. Patane, M. D’Arienzo, M. Fiore, F. Morazzoni, R. Ruffo. Phys. Chem. Chem. Phys., 21, 6021 (2019). DOI: $10.1039 / \mathrm{C} 8 \mathrm{CP} 07023 \mathrm{G}$

[3] Y. Bleu, F. Bourquard, T. Tite, A.-S. Loir, C. Maddi, C. Donnet, F. Garrelie. Front. Chem. 6, 572 (2018). DOI: $10.3389 /$ fchem.2018.00572

[4] K. Ihara, H. Numata, F. Nihey, R. Yuge, H. Endoh, Appl. Nano Mater., 2 (7) 4286 (2019).

DOI: $10.1021 /$ acsanm.9b00746

[5] M.K. Rabchinskii, A.T. Dideikin, D.A. Kirilenko, M.V. Baidakova, V.V. Shnitov, F. Roth, S.V. Konyakhin, N.A. Besedina, S.I. Pavlov, R.A. Kuricyn, N.M. Lebedeva, P.N. Brunkov, A.Ya. Vul'. Scientific Reports, 8, 14154 (2018). DOI: 10.1038/s41598-018-32488-x

[6] J. Robertson. Prog. Sol. St. Chem., 21, 199 (1991). DOI: 10.1016/0079-6786(91)90002-H

[7] A.M. Popov, G.N. Shumkin, N.G. Nikishin. Comp. Nanotechnol., 2, 13 (2014).

[8] J.Y. Huang, S. Chen, Z.F. Ren, G.S. Chen, M.S. Dresselhaus. Nano Lett., 6, 1699 (2006). DOI: 10.1021/n10609910

[9] S. Annas. 53rd Electronic Components and Technology Conference, Proceedings (IEEE, New Orleans, 2003), p. 1691. DOI: 10.1109/ECTC.2003.1216529

[10] H. Birol, T. Maeder, P. Ryser. J. Micromech. Microeng., 17, 50 (2007). DOI: 10.1088/0960-1317/17/1/007

[11] T.N. Lambert, C.C. Luhrs, C.A. Chavez, S. Wakelandb, M.T. Brumbachc, T.M. Alamd. Carbon, 48, 4081 (2010). DOI: 10.1016/j.carbon.2010.07.015

[12] P. Blake, A.H. Castro Neto, K.S. Novoselov, D. Jiang, R. Yang, T.J. Booth, A.K. Geim, E.W. Hill. Appl. Phys. Lett., 91, 063124 (2007). DOI: $10.1063 / 1.2768624$

[13] C.L. Marquardt, R.T. Williams, D.J. Nagel. Mater. Res. Society, 38, 325 (1985). DOI: 10.1557/PROC-38-325

[14] A. Sikora, F. Garrelie, C. Donnet, A.S. Loir, J. Fontaine, J.C. Sanchez-Lopez, T.C. Rojas. J. Appl. Phys., 108, 113516 (2010). DOI: $10.1063 / 1.3510483$

[15] K.P. Acharya, H. Khatri, S. Marsillac, B. Ullrich, P. Anzenbacher, M. Zamkov. Appl. Phys. Lett., 97, 201108 (2010). DOI: $10.1063 / 1.3518481$

[16] I. Kumar, A. Khare. Appl. Surf. Sci., 317, 1004 (2014). DOI: 10.1016/j.apsusc.2014.08.185

[17] S.C. Xu, B.Y. Man, S.Z. Jiang, A.H. Liu, G.D. Hu, C.S. Chen, M. Liu, C. Yang, D.J. Feng, C. Zhang. Laser Phys. Lett., 11, 096001 (2014). DOI: 10.1088/1612-2011/11/9/096001

[18] C12 Advanced Technologies Application Notes: LTCC Carbon Tape (TCS-CARB-1) [Электронный ресурс]. Режим доступа: http://www.c12materials.com

[19] J.J. Gaumet, A. Wakisaka, Y. Shimizu, Y. Tamori. J. Chem. Soc. Faraday Trans., 89(11), 1667 (1993). DOI: $10.1039 / F T 9938901667$

[20] R.E. Franklin. Acta Cryst., 3, 107 (1950). DOI: $10.1107 / \mathrm{S} 0365110 X 50000264$

[21] M. Pawlyta, J.-N. Rouzaud, S. Duber. Carbon, 84, 479 (2015). DOI: 10.1016/j.carbon.2014.12.030

[22] A. Cuesta, P. Dhamelincourt, J. Laureyns, A. Martinez-Alonso, J.M.D. Tascon. J. Mater. Chem., 8, 2875 (1998). DOI: $10.1039 / \mathrm{A} 805841 \mathrm{E}$
[23] N.E.S Sazali, M. Deraman, R. Omar, M.A.R. Othman, M. Suleman, S.A. Shamsudin, N.S.M. Tajuddin, M.F.Y.M. Hanappi, E. Hamdan, N.S.M. Nor, N.H. Basri. AIP Conf. Proc., 1784, 040009 (2016). DOI: 10.1063/1.4966795

[24] S. Navalon, J.R. Herance, M. Alvaro, H. Garcia. Mater. Horiz., 5, 363 (2018). DOI: 10.1039/C8MH00066B

[25] J. Robertson. Mater. Sci. Engineer: Reports, 37, 129 (2002). DOI: $10.1016 / \mathrm{S} 0927-796 \mathrm{X}(02) 00005-0$

[26] T. Xu, S. Yang, J. Lu, Q. Xue, J. Li, W. Guo, Y. Sun. Diamond Related Mater., 10, 1441 (2001). DOI: $10.1016 / \mathrm{S} 0925-9635(00) 00500-8$

[27] J.R. Rani, J. Lim, J. Oh, D. Kim, D. Lee, J.-W. Kim, H.S. Shin, J.H. Kim, S.C. Jun. RSC Adv., 3, 5926 (2013). DOI: $10.1039 /$ C3RA00028A

[28] M.K. Rabchinskii, A.T. Dideikin, D.A. Kirilenko, M.V. Baidakova, V.V. Shnitov, F. Roth, S.V. Konyakhin1, N.A. Besedina, S.I. Pavlov, R.A. Kuricyn, N.M. Lebedeva, P.N. Brunkov, A.Ya. Vul'. Scientific Reports, 8, 14154 (2018). DOI: $10.1038 / \mathrm{s} 41598-018-32488-\mathrm{x}$

[29] L. Chen, Zh. Xu, J. Li, B. Zhou, M. Shan, Y. Li, L. Liu, B. Li, J. Niu. RSC Adv., 4, 1025 (2014). DOI: 10.1039/C3RA46203J

[30] J.F. Watts, J. Wilstenholme. An Introduction to Surface Analysis by XPS and AES (John Wiley\&Sons Ltd, Chichester, West Sussecs, 2003)

[31] E.D. Briggs, M.P. Seach. Practical Surface Analysis by Auger and X-Ray Photoelectron Spectroscopy (John Wiley\&Sons Ltd, Chichester, 1983)

[32] В.И. Нефедов. Рентгеноэлектронная спектроскопия химических соединений: справочник (Химия, М.,1984)

[33] N. Kumar, R. Ramadoss, A.T. Kozakov, S.K. Jothiramalingam, S. Dash., A.K. Tyagi, N.H. Tai., I-Nan Lin. J. Phys. D: Appl. Phys., 46, 275501 (2013). DOI: $10.1088 / 0022-3727 / 46 / 27 / 275501$

[34] P. Piecuch, J. Maruani, G. Delgado-Barrio, S. Wilson. Advances in the Theory of Atomic and Molecular Systems, Dynamics, Spectroscopy, Clusters and Nanostructures (Springer, Dordrecht, Heidelberg, London, N Y., 2009) DOI: $10.1007 / 978-90-481-285-0$

[35] A.C. Ferrari, J. Robertson. Phys. Rev. B, 61, 14095 (2000). DOI: 10.1103/PhysRevB.61.14095

[36] A.C. Ferrari. Sol. State Comm., 143, 47 (2007). DOI: 10.1016/j.ssc.2007.03.052

[37] M.A. Pimenta, G. Dresselhaus, M.S. Dresselhaus, L.G. Cancado, A. Jorioa, R. Saito. Phys. Chem. Chem. Phys., 9, 1276 (2007). DOI: 10.1039/B613962K

[38] A.C. Ferrari, D.M. Basko. Nature Nanotechnol., 8, 235 (2013). DOI: $10.1038 /$ nnano.2013.46

[39] C. Beny-Bassez, J.N. Rouzaud. Scanning Electron Microscopy, 1, 119 (1985).

[40] A. Sadezky, H. Muckenhuber, H. Grothe, R. Niessner, U. Poschl. Carbon, 43, 1731 (2005). DOI: $10.1016 /$ j.carbon.2005.02.018

[41] F. Tuinstra, J.L. Koenig. J. Chem. Phys., 53, 1126 (1970). DOI: $10.1063 / 1.1674108$

[42] L.G. Cancado, K. Takai, T. Enoki, M. Endo. Appl. Phys. Lett., 88, 163106 (2006). DOI: 10.1063/1.2196057

[43] A.C. Ferrari, J. Robertson. Phys. Rev. B, 64, 075414 (2001). DOI: $10.1103 /$ PhysRevB.64.075414

[44] A.C. Ferrari, S.E. Rodil, J. Robertson. Phys. Rev. B, 67, 155306 (2003). DOI: 10.1103/PhysRevB.67.155306 
[45] A. Eckmann, A. Felten, A. Mishchenko, L. Britnell, R. Krupke, K.S. Novoselov, C. Casiraghi, Nano Lett., 12 (8), 3925 (2012). DOI: 10.1021/n1300901a

[46] L.G. Cancado, K. Takai, T. Enoki, M. Endo, Y.A. Kim, H. Mizusaki, N.L. Speziali, A. Jorio, M.A. Pimenta. Carbon, 46, 272 (2008). DOI: 10.1016/j.carbon.2007.11.015

[47] H. Wilhelm, M. Lelaurain, E. Mc Rae. J. Appl. Phys., 84, 6552 (1998). DOI: $10.1063 / 1.369027$

[48] A. Das, B. Chakraborty, A.K. Sood. Bull. Mat. Sci., 31, 579 (2008). DOI: $10.1007 / \mathrm{s} 12034-008-0090-5$ 